\title{
An evaluation of pre-poured selective media for the isolation of Neisseria gonorrhoeae
}

\author{
H. YOUNG and A. MOYES
}

Scottish Gonococcal Reference Laboratory, Department of Medical Microbiology, Edinburgh University Medical School, Teviot Place, Edinburgh EH8 9AG

\begin{abstract}
Fourteen commercial media supplied as pre-poured plates were compared with an inhouse' selective medium for their ability to support the growth of 105 gonococcal isolates (representing a wide variety of serovars encountered in natural infection), 25 meningococcal and 20 Neisseria lactamica isolates, and to inhibit the growth of 71 isolates of non-pathogenic neisseriae and miscellaneous organisms. Only two of the prepoured plate media and the in-house selective medium yielded growth of duplicate cultures of all 105 gonococcal isolates after incubation for $24 \mathrm{~h}$ : one other medium provided growth of all the isolates after incubation for $48 \mathrm{~h}$. The ability of the various media to suppress the growth of the 71 isolates of non-pathogenic neisseriae and miscellaneous organisms ranged from 97.2 to $71.8 \%$ of isolates inhibited. Of the four media that enabled growth of all the gonococcal strains, inhibition was $94.4 \%$ for the inhouse medium, $85.9 \%$ and $80.3 \%$ for the two media on which all gonococci grew after $24 \mathrm{~h}$ and $\mathbf{7 1 . 8 \%}$ for the medium on which all of the gonococci grew after $48 \mathrm{~h}$. Failure of growth of gonococci was associated with: serogroup IA isolates $(p<0.001)$, AHU auxotype $(p<0.001)$ and the presence of vancomycin rather than lincomycin in the selective medium $(p<0.02)$. The use of $10 \%$ blood and a highly nutritious medium based on the original New York City (NYC) or modified New York City (MNYC) formulation were also important in supporting growth of gonococci. One of the main problems in lack of selectivity was a failure to inhibit the growth of yeasts. As effective inhibition of yeasts was obtained with other media containing the same concentration of amphotericin, failure may be due to batch variation of supplement, media preparation, or reduced shelf life of the media. None of the commercially available pre-poured media performed as well as the in-house medium despite the fact that some of the media were prepared to a very similar formula.
\end{abstract}

\section{Introduction}

The definitive diagnosis of gonococcal infection relies on culture, usually on selective media, and identification of Neisseria gonorrhoeae [1]. Most selective media contain a rich nutrient base supplemented with blood, partially lysed by heat (chocolate agar) or completely lysed by saponin; an antimicrobial cocktail is added to inhibit micro-organisms other than pathogenic neisseriae. Details of the main selective media, Thayer Martin (TM) medium and New York City (NYC) medium and their modifications have been reviewed elsewhere [2].

In this laboratory, primary culture for gonococci is performed on modified New York City (MNYC)

Received 1 Feb. 1995; revised version accepted 16 Sept. 1995.

Corresponding author: Dr H. Young. medium containing lysed horse blood $10 \%$ and lincomycin $1 \mathrm{mg} / \mathrm{L}$ [3]. Various pre-poured selective media for culture of gonococci are available commercially but surprisingly few comparative data have been published. Fourteen pre-poured selective media available commercially were evaluated. Their ability to support growth of gonococci, meningococci and $N$. lactamica isolates, and to inhibit growth of 71 isolates of non-pathogenic neisseriae and other miscellaneous organisms was compared with 'in-house' selective and non-selective media.

\section{Materials and methods}

\section{Media}

Fourteen gonococcal selective media were obtained from four manufacturers of pre-poured media (Table 1). All plates were within their expiry date at the time of evaluation. For comparison, an in-house selective 
medium based on the formula for MNYC medium was prepared as described previously [3]; the same medium without antibiotics was included as a control. Each medium was labelled with an identification code to help reduce observer bias (Table 1).

\section{Organisms}

$N$. gonorrhoeae (105) isolates tested included the five WHO reference strains recommended for antibiotic susceptibility testing and 100 clinical isolates (30 penicillinase-producing) representing a wide variety of serovars encountered in natural infection (Table 2). Other organisms tested included $N$. meningitidis (25, mainly clinical isolates including some of known serogroup); $N$ lactamica (20, all clinical isolates); Moraxella catarrhalis (20, all clinical isolates including 19 penicillinase-producing strains); Gemella haemolysans NCTC 10243; $N$. animalis NCTC 10212; $N$. canis NCTC 10296; $N$. caviae NCTC 10293; $N$. cinerea NCTC 10294; $N$. cuniculi NCTC 10297; $N$. denitrificans NCTC 10295; $N$. elongata NCTC 10660; $N$. elongata subsp. glycolytica NCTC 11050; $N$. flavescens NCTC 8263; $N$. ovis NCTC 11018; $N$. pharyngis NCTC $4590 ; N$. mucosa NCTC $10777 ; N$. mucosa var mucosa NCTC 10774; Neisseria sp. NCTC 11049; Escherichia coli (6, including NCTC 11560 and 10418); Proteus mirabilis (6); Pseudomonas aeruginosa (6, including NCTC 10662); Staphylococcus aureus
(6, including NCTC 6571 and S113); Streptococcus agalactiae (6); Candida albicans (4); C. glabrata (1) and C. kefyr (1).

\section{Test protocol}

Saline suspensions equivalent to a McFarland 0.5 standard, $c .10^{8} \mathrm{cfu} / \mathrm{ml}$ were prepared from an overnight culture on in-house non-selective medium. Various dilutions of stock suspensions were used to inoculate in-house selective and non-selective media and the 14 commercial pre-poured media. The entire series of plates was tested with the same suspension dilutions of each organism, inoculated in alphabetical order (Table 1), the in-house non-selective medium being inoculated last and acting as a control. A multi-point inoculator with a pin volume of $1 \mu \mathrm{l}$ was used for inoculation. Cultures were incubated at $37^{\circ} \mathrm{C}$ in a $\mathrm{CO}_{2}$-enriched atmosphere and examined after incubation for $16-24 \mathrm{~h}$ and $40-48 \mathrm{~h}$ : the number of colonies was calculated from the appropriate dilution and counts were expressed as $\mathrm{cfu} / \mathrm{ml}$. All counts were performed in duplicate. Although some spreading of $P$. mirabilis was evident on certain media, the number of discrete colonies could be determined from plates that had only a few colonies present. For organisms expected to grow on selective media (gonococci, meningococci and $N$. lactamica), test inocula were $10^{5}, 10^{4}$ and $10^{3} \mathrm{cfu} / \mathrm{ml}$; thus 'no growth' represented $<100 \mathrm{cfu}$. For organisms expected

Table 1. Gonococcal selective media included in the evaluation

\begin{tabular}{|c|c|c|c|c|c|c|c|c|c|}
\hline \multirow[b]{2}{*}{ Code } & \multirow[b]{2}{*}{ Medium } & \multirow{2}{*}{$\begin{array}{l}\text { Manufacturer/ } \\
\text { code no. }\end{array}$} & \multicolumn{6}{|c|}{ Antibiotics* } & \multirow[b]{2}{*}{ Blood/supplements } \\
\hline & & & $\mathrm{V}$ & $\mathrm{L}$ & $\mathrm{C}$ & A & $\mathrm{T}$ & $\mathrm{N}$ & \\
\hline A & $\begin{array}{l}\text { Modified New York } \\
\text { City }\end{array}$ & In-house & - & 1 & 6.6 & 1 & 5 & - & $\begin{array}{l}\text { Lysed horse blood } 10 \% \text {; yeast dialysate } 2.5 \% \text {; } \\
\text { glucose } 0.1 \%\end{array}$ \\
\hline B & $\begin{array}{l}\text { GC Selective VCNT } \\
\text { (chocolate) }\end{array}$ & Unipath PO136A & 3 & - & 7.5 & - & 5 & 36500 & Heated horse blood $10 \%$; yeast dialysate $4 \%$ \\
\hline $\mathrm{C}$ & $\begin{array}{l}\text { GC Selective VCNT } \\
\text { (lysed) }\end{array}$ & Unipath PO135A & 3 & - & 7.5 & - & 5 & 36500 & Lysed horse blood $5 \%$; yeast dialysate $4 \%$ \\
\hline D & $\begin{array}{l}\text { GC Selective VCAT } \\
\text { (lysed) }\end{array}$ & Ùnipath PO137A & 2 & - & 7.5 & 1 & 3 & - & Lysed horse blood $5 \%$; yeast dialysate $4 \%$ \\
\hline $\mathrm{E}$ & $\begin{array}{l}\text { GC Selective LCAT } \\
\text { (lysed) }\end{array}$ & Unipath PO226A & - & 4 & 7.5 & 1 & 5 & - & Lysed horse blood $5 \%$; yeast dialysate $4 \%$ \\
\hline $\mathrm{F}$ & NYC pluc LCAT & bioMérieux & - & 1 & 6 & 1 & 6.5 & - & Lysed horse blood $10 \% ;$ polyvitex \\
\hline G & Selective chocolate agar & bioMérieux 43241 & 3 & - & 7.5 & 1 & 5 & - & Haemoglobin $10 \mathrm{~g} / \mathrm{L}$; polyvitex; glucose $100 \mathrm{~g} / \mathrm{L}$ \\
\hline $\mathrm{H}$ & NYC plus VCAT & bioMérieux & 2 & - & 7.5 & 1 & 3 & - & Lysed horse blood $10 \%$; polyvitex \\
\hline I & $\begin{array}{l}\text { GC selective medium } \\
\text { with lysed blood }\end{array}$ & Difco $9224-30$ & 3 & - & 7.5 & 0.9 & 5 & - & $\begin{array}{l}\text { Lysed horse blood } 5 \% \text {; VX supplement; glucose } \\
0.21 \%\end{array}$ \\
\hline $\mathrm{J}$ & $\begin{array}{l}\text { Neisseria isolation } \\
\text { medium }\end{array}$ & Difco $9188-30$ & 3 & - & 7.5 & 0.9 & 5 & - & VX supplement \\
\hline $\mathbf{K}$ & $\begin{array}{l}\text { GC selective medium } \\
\text { with haemoglobin }\end{array}$ & Difco $9160-30$ & 3 & - & 7.5 & 0.9 & 5 & - & Haemoglobin $2.5 \mathrm{~g} / \mathrm{L}$; Supplement B \\
\hline $\mathrm{L}$ & $\begin{array}{l}\text { GC selective medium } \\
\text { (chocolate) }\end{array}$ & Difco $9223-30$ & 3 & - & 7.5 & 0.9 & 5 & - & Heated horse blood; VX supplement \\
\hline $\mathbf{M}$ & New York City & Difco $9387-30$ & 2 & - & 7.5 & 1 & 3 & - & $\begin{array}{l}\text { Lysed horse blood } 5 \% \text {, serum } 20 \% \text {, yeast dialysate } \\
2.5 \% \text {; glucose } 0.5 \%\end{array}$ \\
\hline $\mathrm{N}$ & $\begin{array}{l}\text { Modified New York } \\
\text { City }\end{array}$ & Becton Dickinson & 2 & - & 7.5 & 1 & 3 & - & Lysed horse blood $8 \%$; suplex \\
\hline $\mathrm{O}$ & GC Lect & Becton Dickinson & 1 & 2 & 7.5 & 1.5 & 3 & - & Haemoglobin $10 \mathrm{~g} / \mathrm{L}$; Isovitalex \\
\hline $\mathbf{P}$ & $\begin{array}{l}\text { Non-selective modified } \\
\text { New York City }\end{array}$ & In-house & & & & & & & $\begin{array}{l}\text { Lysed horse blood } 10 \% \text {; yeast dialysate } 2.5 \% \text {; } \\
\text { glucose } 0.1 \%\end{array}$ \\
\hline
\end{tabular}

V, vancomycin; L, lincomycin; C, colistin; A, amphotericin; $T$, trimethoprim; $N$, nystatin.

*Antibiotic concentration in $\mathrm{mg} / \mathrm{L}$ except nystatin which is given in units/L. 
Table 2. Serotype and auxotype of 100 clinical gonococcal isolates included in the evaluation

\begin{tabular}{|c|c|c|c|c|c|c|c|c|c|}
\hline \multirow[b]{2}{*}{ Serovar } & \multirow[b]{2}{*}{ Number of isolates } & \multicolumn{8}{|c|}{ Number of isolates of auxotype* } \\
\hline & & A & $\mathbf{P}$ & PA & $\mathrm{AHU}$ & PAU & PHU & PAHU & NR \\
\hline IA-2 & 6 & 0 & 0 & 0 & 5 & 0 & 0 & 0 & 1 \\
\hline IA-4 & 3 & 0 & 0 & 0 & 0 & 0 & 0 & 0 & 3 \\
\hline IA-5 & $2^{\dagger}$ & 0 & 0 & 0 & 1 & 0 & 0 & 0 & 0 \\
\hline IA-6 & 5 & 2 & 0 & 0 & 0 & 0 & 0 & 0 & 3 \\
\hline IA-7 & $1^{\dagger}$ & 0 & 0 & 0 & 0 & 0 & 0 & 0 & 0 \\
\hline IA-16 & 4 & 0 & 0 & 0 & 4 & 0 & 0 & 0 & 0 \\
\hline IA-21 & 3 & 0 & 0 & 0 & 3 & 0 & 0 & 0 & 0 \\
\hline IA-25 & 2 & 0 & 0 & 0 & 2 & 0 & 0 & 0 & 0 \\
\hline IB-1 & 10 & 0 & 0 & 0 & 0 & 0 & 1 & 1 & 8 \\
\hline IB-2 & 7 & 0 & 0 & 0 & 0 & 0 & 0 & 1 & 6 \\
\hline IB-3 & 7 & 1 & 4 & 0 & 0 & 0 & 0 & 0 & 2 \\
\hline IB-5 & 2 & 1 & 1 & 0 & 0 & 0 & 0 & 0 & 0 \\
\hline IB-6 & 8 & 0 & 5 & 0 & 0 & 0 & 0 & 0 & 3 \\
\hline IB-7 & 5 & 0 & 3 & 0 & 0 & 0 & 0 & 0 & 2 \\
\hline IB-8 & 4 & 2 & 1 & 0 & 0 & 0 & 0 & 0 & 1 \\
\hline IB-15 & 3 & 0 & 0 & 3 & 0 & 0 & 0 & 0 & 0 \\
\hline IB-17 & 7 & 0 & 0 & 0 & 0 & 0 & 0 & 0 & 7 \\
\hline IB-19 & 2 & 0 & 2 & 0 & 0 & 0 & 0 & 0 & 0 \\
\hline IB-25 & 2 & 0 & 2 & 0 & 0 & 0 & 0 & 0 & 0 \\
\hline IB-26 & 1 & 0 & 0 & 0 & 0 & 0 & 1 & 0 & 0 \\
\hline IB-29 & 2 & 0 & 0 & 0 & 0 & 2 & 0 & 0 & 0 \\
\hline IB-31 & 1 & 0 & 0 & 0 & 0 & 0 & 0 & 0 & 1 \\
\hline IB- $00^{\ddagger}$ & 13 & 0 & 0 & 0 & 0 & 0 & 0 & 0 & 13 \\
\hline Total & 100 & 6 & 18 & 3 & 15 & 2 & 2 & 2 & 50 \\
\hline
\end{tabular}

${ }^{*}$ Requirement for: A, arginine; $\mathrm{P}$, proline; $\mathrm{H}$, hypoxanthine; $\mathrm{U}$, uracil; NR, non-requiring.

${ }^{\dagger}$ One IA-5 isolate and the IA-7 isolate failed to grow on any of the auxotyping media.

${ }^{\ddagger}$ Non-typable strains.

to be inhibited by selective media (non-pathogenic neisseriae and non-neisseriae), test inocula ranged from $10^{8}$ to $10^{3} \mathrm{cfu} / \mathrm{ml}$; thus 'no growth' represented complete inhibition of $10^{5} \mathrm{cfu}$.

Statistical analysis was by the $\chi^{2}$ test with the Minitab PC software package.

\section{Results}

\section{Gonococci}

The performance of media in culturing 105 gonococcal isolates is summarised in Table 3 . The only media to grow all 105 isolates in duplicate after incubation for $24 \mathrm{~h}$ were the in-house selective medium A, commercial media $\mathrm{F}$ and $\mathrm{N}$, and the in-house non-selective control medium, $\mathrm{P}$; medium $\mathrm{L}$ supported growth of all isolates but only after incubation for $48 \mathrm{~h}$. After incubation for $24 \mathrm{~h}$ the vast majority of duplicate cultures gave identical results while after incubation for $48 \mathrm{~h}$ there was total concordance. Overall performance ranged from growth of $78.1 \%$ of strains (medium $\mathrm{J}$ ) to $100 \%$ (media A, F and $\mathrm{N}$ ) after incubation for $24 \mathrm{~h}$ and $88.6 \%$ (medium J) to $100 \%$ (media $\mathrm{A}, \mathrm{F}, \mathrm{N}$ and $\mathrm{L}$ ) after incubation for $48 \mathrm{~h}$. Mean counts after 48 -h culture on selective media ranged from $1.28 \times 10^{8} \mathrm{cfu} / \mathrm{ml}$ (medium B) to $2.02 \times 10^{8} \mathrm{cfu} / \mathrm{ml}$ (medium N). The in-house selective medium (A) gave a count of $1.91 \times 10^{8} \mathrm{cfu} /$ $\mathrm{ml}$ compared to $2.21 \times 10^{8} \mathrm{cfu} / \mathrm{ml}$ on non-selective control medium (P) indicating that the cut-off for failure to grow on the selective media was $c .200 \mathrm{cfu}$.
Table 3. Sensitivity of gonococcal selective media*

\begin{tabular}{lcc}
\hline & \multicolumn{2}{c}{ Number of isolates (\%) cultured at } \\
\cline { 2 - 3 } Medium & $24 \mathrm{~h}$ & $48 \mathrm{~h}$ \\
\hline $\mathrm{A}$ & $210(100)$ & $210(100)$ \\
$\mathrm{B}$ & $200(95.2)$ & $206(98.1)$ \\
$\mathrm{C}$ & $176(83.8)$ & $188(89.5)$ \\
$\mathrm{D}$ & $194(92.4)$ & $202(96.2)$ \\
$\mathrm{E}$ & $193(91.9)$ & $200(95.2)$ \\
F & $210(100)$ & $210(100)$ \\
G & $194(92.4)$ & $202(96.2)$ \\
H & $202(96.2)$ & $204(97.1)$ \\
I & $174(82.9)$ & $196(93.3)$ \\
J & $164(78.1)$ & $186(88.6)$ \\
K & $176(83.8)$ & $194(92.4)$ \\
L & $201(95.7)$ & $210(100)$ \\
M & $178(84.8)$ & $196(93.3)$ \\
N & $210(100)$ & $210(100)$ \\
O & $200(95.2)$ & $204(97.1)$ \\
P & $210(100)$ & $210(100)$ \\
\hline
\end{tabular}

${ }^{*}$ One hundred and five isolates tested in duplicate $(n=210)$.

The failure of media to support the growth of certain serovars is summarised in Table 4. The overall failure rate after incubation for $48 \mathrm{~h}$ of 100 clinical isolates tested on 15 selective media was $4.2 \%$ (64 of 1500). The failure rate of $14.1 \%$ ( 55 of 390 ) with serovar IA isolates was significantly higher than the rate of $0.8 \%$ ( 9 of 1110) found with serovar IB isolates $\left(\chi^{2}=124.8\right.$; $\mathrm{p}<0.001$ ). Generally, the same isolates of gonococci failed to grow on certain media. For example: one IA-5/ AHU and one or more IA-21/AHU isolates were the only failures associated with media $\mathrm{B}, \mathrm{D}, \mathrm{G}, \mathrm{H}$ and $\mathrm{O}$ (all vancomycin-containing media); in addition to failures with isolates IA-5/AHU and IA-21/AHU, medium 
E (lincomycin) and medium $M$ (vancomycin) failed to support growth of one IA-16/AHU and one IA-4/NR isolate, respectively; medium I (vancomycin) and medium $\mathrm{K}$ (vancomycin) both failed with one nontypable IB/NR isolate and with two IA-4/NR and three IA-2/AHU isolates; medium $\mathrm{C}$ (vancomycin) failed with three IA-2/AHU isolates, two IA-4/NR 2 isolates, one IA-5/AHU isolate, three IA-21/AHU isolates and one non-typable IB/NR isolate; medium $\mathbf{J}$ (vancomycin) failed with one IA-2/AHU isolate, one IA-4/NR isolate, one IA-5/AHU, three IA-21/AHU isolates, one IB-1/NR isolate and five non-typable IB/NR isolates.

Vancomycin-containing media accounted for 93.2\% (59 of 64) of all growth failures and the overall failure rate in relation to the total number of challenges was $1.7 \%(5$ of 300) for media containing lincomycin and $4.9 \%$ (59 of 1200) for media containing vancomycin $\left(\chi^{2}=6.2\right.$; $\mathrm{p}<0.02$ ). All five failures on lincomycin-containing medium occurred with the medium containing $4 \mathrm{mg} / \mathrm{L}$ (F) and none on the two media containing $1 \mathrm{mg} / \mathrm{L}$ (A and $F$ ).

The majority of growth failures, $76.6 \%$ (49 of 64 ), were with strains of the AHU auxotype and the remainder were with non-requiring strains (Table 4). Failure rates were $21.8 \%$ (49 of 225 ) for AHU strains, $2 \%$ (15 of 750) for non-requiring strains and $0 \%(0$ of 525$)$ for strains of other auxotypes (AHU strains versus non-requiring strains, $\chi^{2}=110.4 ; \mathrm{p}<0.001$; non-requiring strains versus isolates of other auxotypes, $\chi^{2}=10.63$; $\mathrm{p}<0.01)$.

Table 4. Serotype of gonococci failing to grow on selective media after incubation for $48 \mathrm{~h}$

\begin{tabular}{lcccc}
\hline & $\begin{array}{c}\text { Number of } \\
\text { isolates } \\
\text { tested }\end{array}$ & $\begin{array}{c}\text { Total challenge } \\
\text { from 15 } \\
\text { selective } \\
\text { media }\end{array}$ & $\begin{array}{c}\text { Number (\%) } \\
\text { of cultures } \\
\text { not } \\
\text { growing }\end{array}$ & $\begin{array}{c}\text { Number of } \\
\text { media with } \\
\text { growth } \\
\text { failure }\end{array}$ \\
\hline IA-2 & 6 & 90 & $7^{*}(8)$ & 3 \\
IA-4 & 3 & 45 & $6^{\dagger}(13.3)$ & 4 \\
IA-5 & 2 & 30 & $11^{*}(36.7)$ & 11 \\
IA-6 & 5 & 75 & 0 & 0 \\
IA-7 & 1 & 15 & 0 & 0 \\
IA-16 & 4 & 60 & $1^{*}(1.7)$ & 1 \\
IA-21 & 3 & 45 & $29^{*}(64.5)$ & 11 \\
IA-25 & 2 & 30 & $1^{*}(3.3)$ & 1 \\
IB-1 & 10 & 150 & $1^{\dagger}(0.7)$ & 1 \\
IB-2 & 7 & 105 & 0 & 0 \\
IB-3 & 7 & 105 & 0 & 0 \\
IB-5 & 2 & 30 & 0 & 0 \\
IB-6 & 8 & 120 & 0 & 0 \\
IB-7 & 5 & 75 & 0 & 0 \\
IB-8 & 4 & 60 & 0 & 0 \\
IB-15 & 3 & 45 & 0 & 0 \\
IB-17 & 7 & 105 & 0 & 0 \\
IB-19 & 2 & 30 & 0 & 0 \\
IB-25 & 2 & 30 & 0 & 0 \\
IB-26 & 1 & 15 & 0 & 0 \\
IB-29 & 2 & 30 & 0 & 0 \\
IB-31 & 1 & 15 & 0 & 0 \\
IB-00 & 13 & 195 & 0 & 0 \\
Total & 100 & 1500 & $04.1)$ & 0 \\
\hline$*-140$ & & 0 & 0 \\
\hline
\end{tabular}

* AHU auxotype strains.

${ }^{\dagger}$ Non-requiring strains.
Although serovar IA and the AHU auxotype were associated with failure to grow, there was a considerable variation between serovar IA isolates: serovars IA-2 ( 5 of $6 \mathrm{AHU}$ ), IA-7 (non-auxotypable), and IA-25 (2 of 2 AHU) showing similar failure rates $(p<0.05)$, serovars IA-5 ( 1 of $2 \mathrm{AHU}$ ) and IA-21 (3 of 3 AHU) significantly higher failure rates $(p<0.05)$, and serovars IA- 6 ( 0 of 5 AHU) and IA-16 (4 of 4 AHU) significantly lower failure rates $(p<0.05)$ when compared with all serovar IA isolates.

\section{Meningococci}

After incubation for $24 \mathrm{~h}$ the performance of media in supporting growth of meningococci was $92 \%$ ( 23 of 25 ) with media D and J; $96 \%$ (24 of 25 ) with media B, C, E, G, H, I, K, L, M, N and O; and $100 \%$ with media A, $\mathrm{F}$ and $\mathrm{P}$. After incubation for $48 \mathrm{~h}$ results were identical except for media $D$ and $E$ on each of which a further isolate grew. Mean counts after culture for $48 \mathrm{~h}$ on selective media ranged from $3.13 \times 10^{8} \mathrm{cfu} / \mathrm{ml}$ (medium B) to $4.53 \times 10^{8} \mathrm{cfu} / \mathrm{ml}$ (medium 0 ). The in-house selective medium A gave a count of $4.36 \times 10^{8} \mathrm{cfu} / \mathrm{ml}$ while the non-selective control medium $P$ gave a count of $4.40 \times 10^{8} \mathrm{cfu} / \mathrm{ml}$. These results suggest that the cutoff for failure to grow on the selective media was $c$. $450 \mathrm{cfu}$. The same meningococcal strain, a non-groupable type 15 strain sensitive to penicillin and sulphadiazine, was responsible for all growth failures.

\section{N. lactamica}

All 20 strains of $N$. lactamica grew on all of the media after incubation for $24 \mathrm{~h}$. Mean counts after $48 \mathrm{~h}$ ranged from $1.28 \times 10^{8} \mathrm{cfu} / \mathrm{ml}$ (medium B) to $2.14 \times 10^{8} \mathrm{cfu} /$ $\mathrm{ml}$ (medium $\mathrm{N}$ ). The in-house selective medium A gave a count of $1.88 \times 10^{8} \mathrm{cfu} / \mathrm{ml}$ while the non-selective control medium P gave a count of $2.08 \times 10^{8} \mathrm{cfu} / \mathrm{ml}$.

\section{Non-pathogenic neisseriae and miscellaneous organisms}

The results of testing the 71 non-pathogenic neisseriae and miscellaneous organisms in duplicate are summarised in Table 5. None of the selective media inhibited all of the organisms after incubation for $48 \mathrm{~h}$ although medium G gave $100 \%$ inhibition after incubation for $24 \mathrm{~h}$. After incubation for $48 \mathrm{~h}$, inhibition ranged from $72.5 \%$ (medium L) to $97.9 \%$ (medium G): their performance in supporting the growth of gonococci after $48 \mathrm{~h}$ was $100 \%$ and $96.2 \%$, respectively. Details of the organisms that grew on the various selective media are summarised in Table 6. Generally, results of duplicate cultures were concordant, apart from $N$. cinerea and one of the strains of $N$. mucosa which often grew on only one of the duplicate plates. Although results in Table 6 are based on 'growth' or 'no growth' the extent of growth was often substantially reduced compared with the nonselective control medium $P$. 
Table 5. Specificity of gonococcal selective media; nonpathogenic neisseriae and miscellaneous organisms tested in duplicate*

\begin{tabular}{lcc}
\hline & \multicolumn{2}{c}{ Number of isolates (\%) inhibited at } \\
\cline { 2 - 3 } Medium & $24 \mathrm{~h}$ & $48 \mathrm{~h}$ \\
\hline $\mathrm{A}$ & $140(98.6)$ & $135(95.1)$ \\
$\mathrm{B}$ & $138(97.2)$ & $124(87.3)$ \\
$\mathrm{C}$ & $128(90.1)$ & $126(88.7)$ \\
$\mathrm{D}$ & $138(97.2)$ & $132(93)$ \\
$\mathrm{E}$ & $138(97.2)$ & $135(95.1)$ \\
$\mathrm{F}$ & $128(90.1)$ & $123(86.6)$ \\
$\mathrm{G}$ & $142(100)$ & $139(97.9)$ \\
$\mathrm{H}$ & $134(94.4)$ & $125(88)$ \\
$\mathrm{I}$ & $134(94.4)$ & $131(92.3)$ \\
$\mathrm{J}$ & $126(88.7)$ & $123(86.6)$ \\
$\mathrm{K}$ & $138(97.2)$ & $135(95.1)$ \\
$\mathrm{L}$ & $116(81.7)$ & $103(72.5)$ \\
$\mathrm{M}$ & $138(97.2)$ & $136(95.8)$ \\
$\mathrm{N}$ & $118(83.1)$ & $115(81)$ \\
$\mathrm{O}$ & $138(97.2)$ & $135(95.1)$ \\
$\mathrm{P}$ & 0 & 0 \\
\hline
\end{tabular}

${ }^{*} n=142$.

\section{Discussion}

Selective media improve the cultural diagnosis of gonorrhoea by preventing the growth of other bacteria which may mask the presence of gonococcal colonies or inhibit the growth of gonococci directly. Many organisms present in the normal endocervical flora inhibit gonococci [4-9]. In assessing the suitability of pre-poured selective media the most important factor is the ability to support the growth of all gonococcal isolates, followed by the effective inhibition of a wide range of other bacteria. As gonococcal infection can occur at levels as low as $10^{2} \mathrm{cfu} / \mathrm{ml}$, and other organisms may often be present at levels well in excess of $10^{6} \mathrm{cfu} / \mathrm{ml}$ [10] cut-off values of c. $10^{2} \mathrm{cfu} / \mathrm{ml}$ for growth of gonococci and $10^{4}-10^{6} \mathrm{cfu} / \mathrm{ml}$ for inhibition of non-pathogenic neisseriae and miscellaneous organisms were chosen to represent a meaningful test of the selective media in clinical practice. The inclusion of
AHU strains is important in comparing lincomycin and vancomycin as selective agents; Reichart et al. [11] included only $2.7 \%$ of such isolates in their study comparing GC-Lect and modified Thayer Martin (MTM) medium but stressed that future studies should include more AHU isolates. In the present study $15 \%$ of isolates were AHU strains.

In addition to the in-house selective media only two of the commercial pre-poured selective media ( $\mathrm{F}$ and $\mathrm{N}$ ) supported growth of all 105 isolates of gonococci in duplicate after incubation for $24 \mathrm{~h}$ (Table 3); although medium $\mathrm{L}$ yielded growth of all 105 isolates after incubation for $48 \mathrm{~h}$ it failed to support the growth of three isolates in duplicate and three isolates in one of the duplicate cultures after $24 \mathrm{~h}$. When gonococci grew on a particular medium the counts were generally similar to all other media. A non-groupable type 15 isolate of meningococcus failed to grow on media $\mathrm{L}$ and $\mathrm{N}$ and these media also allowed an unacceptable percentage of non-gonococcal neisseriae or miscellaneous organisms to grow (28.2\% and $19.7 \%$ respectively). Although medium $\mathrm{F}$ was the only commercial selective media to support the growth of all gonococci and meningococci, it allowed $14.1 \%$ of non-gonococcal neisseriae or miscellaneous organisms to grow compared with $5.6 \%$ for the in-house medium; this difference in inhibition was due to the complete failure of medium $F$ to inhibit growth of yeasts, a serious problem, as certain strains of Candida albicans produce a substance inhibitory to gonococci $[8,9]$ The other organisms growing on medium $\mathrm{F}$ and the in-house selective medium $\mathrm{A}$ were identical and included $G$. haemolysans, $N$. cinerea, $N$. muscosa var mucosa and a methicillin-resistant staphylococcal strain. Clearly, none of the commercial media in this trial performed as well overall as the in-house selective medium.

In general, media that contained $10 \%$ blood (A, B, F and $\mathrm{H})$ gave significantly better results for supporting the growth of gonococci after incubation for $48 \mathrm{~h}$ (mean

Table 6. Growth of 71 non-pathogenic neisseriae and miscellaneous organisms cultured in duplicate on gonococcal selective media for $48 \mathrm{~h}$

\begin{tabular}{|c|c|c|c|c|c|c|c|c|c|c|c|c|c|c|c|c|}
\hline \multirow[b]{2}{*}{ Organism } & \multirow{2}{*}{$\begin{array}{c}\text { Number } \\
\text { of } \\
\text { isolates }\end{array}$} & \multicolumn{15}{|c|}{ Number $(\%)$ of isolates growing on corresponding medium } \\
\hline & & A & $\mathbf{B}$ & $\mathrm{C}$ & $\mathrm{D}$ & $\mathrm{E}$ & $\mathbf{F}$ & G & $\mathbf{H}$ & I & $\mathbf{J}$ & $\mathbf{K}$ & $\mathbf{M}$ & $\mathbf{L}$ & $\mathbf{N}$ & $\mathbf{O}$ \\
\hline Candida spp. & $6^{*}$ & 0 & 4 & 5 & 0 & 0 & 6 & 0 & 5 & 0 & 6 & 0 & 5 & 0 & 5 & 0 \\
\hline Neisseria spp. & $14^{+}$ & $2^{\ddagger}$ & 2 & $2^{\ddagger \S}$ & $2^{\ddagger \S}$ & $2^{\ddagger}$ & $2^{\ddagger}$ & $2^{\ddagger}$ & $2^{\ddagger}$ & $2^{\S}$ & $1^{\ddagger}$ & $2^{\ddagger}$ & $2^{\S}$ & 1 & $1^{\S}$ & $2^{\S}$ \\
\hline M. catarrhalis & 20 & 0 & 0 & 0 & 0 & 0 & 0 & 0 & 0 & 0 & 0 & 0 & 2 & 0 & 0 & 0 \\
\hline G. haemolysans & 1 & 1 & 0 & 0 & 0 & 0 & 1 & 0 & 0 & 0 & 0 & 0 & 0 & 0 & 0 & 0 \\
\hline E. coli & 6 & 0 & 0 & 0 & 0 & 0 & 1 & 0 & 0 & 0 & 0 & 0 & 0 & 0 & 0 & 0 \\
\hline P. mirabilis & 6 & 0 & 3 & 2 & 4 & 1 & 0 & 0 & 2 & 3 & 3 & 2 & 6 & 2 & 3 & 1 \\
\hline Ps. aeruginosa & 6 & 0 & 0 & 0 & 0 & 0 & 0 & 0 & 0 & 1 & 0 & 0 & 5 & 0 & 0 & 0 \\
\hline S. aureus & 6 & 1 & 0 & 0 & 0 & 1 & 1 & 0 & 0 & 0 & 0 & 0 & 0 & 0 & 2 & 1 \\
\hline St. pyogenes & 6 & 0 & 0 & 0 & 0 & 0 & 0 & 0 & 0 & 0 & 0 & 0 & 0 & 0 & 3 & 0 \\
\hline Total & 71 & $\begin{array}{l}4 \\
(5.6)\end{array}$ & $\begin{array}{c}9 \\
(12.7)\end{array}$ & $\begin{array}{c}9 \\
(12.7)\end{array}$ & $\begin{array}{l}6 \\
(8.5)\end{array}$ & $\begin{array}{l}4 \\
(5.6)\end{array}$ & $\begin{array}{l}10 \\
(14.1)\end{array}$ & $\begin{array}{l}2 \\
(2.8)\end{array}$ & $\begin{array}{c}9 \\
(12.7)\end{array}$ & $\begin{array}{l}6 \\
(8.5)\end{array}$ & $\begin{array}{l}10 \\
(14.1)\end{array}$ & $\begin{array}{l}4 \\
(5.6)\end{array}$ & $\begin{array}{l}20 \\
(28.2)\end{array}$ & $\begin{array}{l}3 \\
(4.2)\end{array}$ & $\begin{array}{l}14 \\
(19.7)\end{array}$ & $\begin{array}{l}4 \\
(5.6)\end{array}$ \\
\hline
\end{tabular}

Note: media were tested in duplicate and in most cases growth occurred on both duplicates (see text).

${ }^{*}$ C. albicans (4), C. glabrata (1), C. kefyr (1).

${ }^{\dagger} N$. animalis (1), N. canis (1), N. caviae (1), N. cinerea ${ }^{\ddagger}(1), N$. cuniculi (1), N. denitrificans (1), N. elongata (1), N. elongata subsp. glycolytica (1), N. flavescens (1), N. mucosa (1), N. mucosa var mucosa $a^{\S}$ (1), N. ovis (1), N. pharyngis (1), Neisseria sp. NCTC 11049 (1).

${ }^{+}$and ${ }^{\S}$ one isolate included as growth was inhibited on one of the duplicate cultures. 
98.8\%) than media that contained $5 \%$ blood (C, D, E, I and $\mathrm{M}$; mean $93.5 \%$; $<<0.001$ ) or haemoglobin $(\mathrm{G}, \mathrm{K}$ and $\mathrm{O}$; mean $95.2 \%, \mathrm{p}<0.01)$. Media containing lincomycin performed significantly better than those containing vancomycin; both the media ( $\mathrm{A}$ and $\mathrm{F}$ ) that enabled the growth of all gonococcal and meningococcal strains contained lincomycin $(1 \mathrm{mg} / \mathrm{L})$, whilst all of the gonococci grew on only two (L and $\mathrm{N}$ ) of 11 vancomycin-containing media. All growth failures with lincomycin occurred with AHU auxotype strains on the medium containing $4 \mathrm{mg} / \mathrm{L}$ but not with the media containing $1 \mathrm{mg} / \mathrm{L}$ suggesting that a concentration of $4 \mathrm{mg} / \mathrm{L}$ is inhibitory to certain strains of gonococci. All the media containing vancomycin failed to support the growth of the same non-groupable type 15 meningococcal isolate which was known to be sensitive to penicillin and sulphadiazine and may also be sensitive to vancomycin. Vancomycin in selective media is known to have an inhibitory effect on gonococci $[12,13]$ and is associated with the AHU auxotype $[14,15]$ which in turn shows a correlation with serogroup IA isolates [1618]. In 1978 the antibiotic formulation of the original NYC medium [19] was modified by reducing the vancomycin from 3 to $2 \mathrm{mg} / \mathrm{L}$ [20] because $3 \mathrm{mg} / \mathrm{L}$ was inhibitory to the growth of as many as $10 \%$ of gonococcal strains $[13,21]$. However, these results suggest that the four media containing vancomycin $2 \mathrm{mg} / \mathrm{L}$ performed significantly less well than the two media containing lincomycin $1 \mathrm{mg} / \mathrm{L}$ : after incubation for $48 \mathrm{~h}$ the percentages of gonococci growing were $96.2,97.1,93.3$ and $100 \%$ for the vancomycin media compared with $100 \%$ for the two lincomycin-containing media $(p<0.01)$. Interestingly, the medium containing vancomycin $2 \mathrm{mg} / \mathrm{L}$ that yielded growth of all gonococcal isolates was the second least selective medium allowing growth of $19 \cdot 7 \%$ of non-pathogenic neisseriae and miscellaneous organisms. Although an increased growth of unwanted organisms on rectal and pharyngeal cultures has been associated with media containing lincomycin $1 \mathrm{mg} / \mathrm{L}$ [22] this can be reduced by decreasing the level of glucose in the media [23]. Furthermore, as most contaminants appear after incubation for $>24 \mathrm{~h}$ this is not a major problem when plates are examined on day 1 . The NYC and MNYC formulation supports luxuriant growth which means that gonococcal colonies are clearly visible by $24 \mathrm{~h}$ in the majority of primary cultures [3,24]. GC-Lect medium (medium $\mathrm{O}$ ) contains both vancomycin $2 \mathrm{mg} /$ $\mathrm{L}$ and lincomycin $1 \mathrm{mg} / \mathrm{L}$ but performed no better than media containing lincomycin or vancomycin alone. Reichert et al. found GC-Lect medium performed better than MTM medium containing vancomycin $3 \mathrm{mg} / \mathrm{L}$; however, the isolates missed by the MTM medium were not susceptible to vancomycin, all having vancomycin MICs $\geqslant 4$ [11]. This supports earlier findings comparing MNYC medium containing lincomycin $1 \mathrm{mg} / \mathrm{L}$ with Thayer Martin medium containing vancomycin $4 \mathrm{mg} / \mathrm{L}$ [3]; none of the strains isolated only on MNYC medium was sensitive to vancomycin at the concentration present in the Thayer Martin medium. The improved perfor- mance with lincomycin-containing media may be related to the greater safety margin with lincomycin (MIC usually 16 times the concentration present in the medium) than with vancomycin (MIC usually 2-4-fold greater than the corresponding medium concentration). This increased safety margin combined with the better nutritional value of MNYC medium may be particularly important in the case of small inocula [3]. Although Martin-Lewis medium was not included in this evaluation it was shown recently that NYC medium containing vancomycin $2 \mathrm{mg} / \mathrm{L}$ markedly enhanced the recovery of gonococci from clinical specimens when compared with Martin-Lewis medium which contains vancomycin $4 \mathrm{mg} / \mathrm{L}$ [24].

Overall, the 15 selective media were significantly poorer $(p<0.001)$ at supporting the growth of the 26 serogroup IA clinical isolates $(86 \%)$ than the 74 IB clinical isolates $(99.2 \%)$, supporting the view that the failure of certain selective media to support the growth of gonococci is due to a combination of nutritional inadequacy - possibly related to a low concentration of blood - and an inhibitory effect of vancomycin. Of the IA clinical isolates included in this evaluation $57.7 \%$ (15 of 26) were of the AHU auxotype. AHU strains may be even more prevalent in certain non-selected populations; serovar IA-2 has been shown to account for the majority of serovar IA infections and also to account for as much as $96.8 \%$ [18] and 98\% [16] of AHU strains. In contrast there is a correlation between serogroup IB isolates and the non-requiring (NR) auxotype which accounted for $58.1 \%$ (43 of 74) of IB isolates in the test strains and $64.5 \%$ [18] and $63.2 \%$ of IB isolates in non-selected populations [25]. Although isolates of serovar IA and the AHU auxotype were associated with failure to grow there was a considerable serovar variation, with isolates of certain minor serovars such as IA-5 and IA-21 showing the strongest correlation. This has important implications for the detection and control of these minor serovars within the community and could be significant in the overall epidemiology of gonococcal infection.

Failure to inhibit yeasts was a significant factor in the lack of selectivity of several media. Only two media (B and $C$ ) contained nystatin, which showed extremely poor inhibition of yeasts. Amphotericin has been shown to be superior to nystatin in suppressing yeast contaminants in selective media [26]. In the present study, most media containing amphotericin $\geqslant 0.9 \mathrm{mg} / \mathrm{L}$ inhibited yeasts completely. However, media F, H, J, L and $\mathrm{N}$ which contain similar concentrations of amphotericin failed to inhibit yeasts; this may be due to batch variation of supplement, media preparation, or reduced shelf-life of the media. Interestingly, manufacturers of media that failed to inhibit yeasts also produced media containing the same concentration of amphotericin that gave complete inhibition.

Colistin was generally effective in inhibiting non- 
gonococcal neisseriae and gram-negative bacilli, although medium L (colistin $7.5 \mathrm{mg} / \mathrm{L}$ ) allowed the growth of two Moraxella, five Pseudomonas and six Proteus strains. All the media, apart from medium N, allowed the growth of $N$. cinerea in at least one of the duplicate cultures and most of the media also allowed $N$. mucosa var mucosa to grow. In practice the latter organism is rarely isolated [27] and can be distinguished readily from $N$. gonorrhoeae by sugar utilisation tests. $N$. cinerea is also a relatively rare isolate but is of much greater significance as, not only is it able to grow on gonococcal selective media [28], but it may cause problems in identification $[29,30]$ and result in the misdiagnosis of gonorrhoea. Medium $\mathrm{N}$, the only medium to inhibit $N$. cinerea, was poor at inhibiting $P$. mirabilis gram-positive bacteria and yeasts.

Only three media (A, F and G) inhibited all six strains of $P$. mirabilis, suggesting that the failure of the other media, which contained similar concentrations of trimethoprim, must be due to problems in media preparation or stability. The same reasons may explain the failure of media $\mathrm{N}$ and $\mathrm{O}$ to inhibit certain strains of streptococci and staphylococci. Media (A, E and F) containing lincomycin failed to inhibit the MRSA isolate, in keeping with the poorer inhibition of grampositive organisms by lincomycin in comparison to vancomycin [21] but this is much less important than the inhibitory effect of vancomycin on gonococci.

These results support previous findings that the improved nutritional status of media based on the original NYC medium $[19,26]$ or the much simpler MNYC formulation [3] provides superior performance both in terms of the number of positive clinical cultures and the rapidity and quality of growth when compared with conventional media $[3,22-24,31]$. In addition, the results support earlier reports of the superior performance of media containing lincomycin in place of vancomycin in both chocolate agar [21] and MNYC medium [22, 23].

In conclusion, none of the commercially available prepoured media performed as well as the in-house medium in spite of the fact that some of the media were prepared to a very similar formula. We consider that manufacturers are providing too great a selection of media, some of which perform inadequately, probably due to a combination of factors including the level of nutrition, inappropriate choice of antibiotic supplements, and too long a shelf-life. The results of this evaluation and a review of the literature suggest that the use of $10 \%$ blood, a highly nutritious medium (based on the original NYC or MNYC formulation), and lincomycin in place of vancomycin, are crucial to the production of an effective selective medium. We urge manufacturers to take note of these points. A rational restriction in the variety of selective media is likely to decrease production costs, allow a shorter shelf-life and improve the overall performance.
We thank the following companies who supplied plates: Becton Dickinson UK Ltd, Cowley, Oxford OX4 3LY; bioMérieux UK Ltd, Basingstoke, Hampshire RG22 6HY; Difco Laboratories Ltd, West Molesy, Surrey KT8 2SE and Unipath Ltd, Basingstoke, Hampshire, RG24 8PW.

\section{References}

1. Adler MW. Diagnostic treatment and reporting criteria for gonorrhoea in sexually transmitted disease clinics in England and Wales. 1 Diagnosis. Br J Vener Dis 1978; 54: 10-14.

2. Young $\mathrm{H}$, Reid KG. Immunological diagnosis of gonococcal infection. In: Young $\mathrm{H}$, McMillan A (eds) Immunological diagnosis of sexually transmitted diseases. New York, Marcel Dekker Inc. 1988: 77-116.

3. Young H. Cultural diagnosis of gonorrhoea with modified New York City (MNYC) medium. Br J Vener Dis 1978; 54: 36-40.

4. Saigh JH, Sanders CC, Sanders WE. Inhibition of Neisseria gonorrhoeae by aerobic and facultatively anaerobic components of the endocervical flora: evidence for a protective effect against infection. Infect Immun 1978; 19: 704-710.

5. Kraus SJ, Geller RC, Perkins GH, Rhoden DL. Interference of Neisseria gonorrhoeae growth by other bacterial species. $J$ Clin Microbiol 1976; 4: 288-295.

6. Kay D, Levinson M. In vitro inhibition of growth of Neisseria gonorrhoeae by growth of genital microorganisms. Sex Transm Dis 1977; 4: 1-3.

7. Shtibel R. Inhibition of growth of $N$. gonorrhoeae by bacterial interference. Can J Microbiol 1976; 22: 1430-1436.

8. Hipp SS, Lawton WD, Chen NC, Gaafar HA. Inhibition of Neisseria gonorrhoeae by a factor produced by Candida albicans. Appl Microbiol 1974; 27: 192-201.

9. Hipp SS, Lawton WD, Savage M, Gaafar HA. Selective interaction of Neisseria gonorrhoeae and Candida albicans and its possible role in clinical specimens. J Clin Microbiol 1975; 1: 476-477.

10. Young H, Sarafian SK, Harris AB, McMillan A. Non-cultural detection of Neisseria gonorrhoeae in cervical and vaginal washings. J Med Microbiol 1983; 16: 183-191.

11. Reichart CA, Rupkey LM, Brady WE, Hook EW. Comparison of GC-Lect and modified Thayer-Martin media for isolation of Neisseria gonorrhoeae. J Clin Microbiol 1989; 27: 808-811.

12. Windall, JJ, Hall MM, Washington JA, Douglass TJ, Weed LA. Inhibitory effects of vancomycin on Neisseria gonorrhoeae in Thayer-Martin medium. J Infect Dis 1980; 142: 775.

13. Brorson J-E, Holmberg I, Nygren B, Seeberg S. Vancomycinsensitive strains of Neisseria gonorrhoeae. A problem for the diagnostic laboratory. $\mathrm{Br} J$ Vener Dis 1973; 49: 452-453.

14. Mirrett S, Reller LB, Knapp JS. Neisseria gonorrhoeae strains inhibited by vancomycin in selective media and correlation with auxotype. J Clin Microbiol 1981; 14: 94-99.

15. Exner AC, Shinners EN, Pace PJ, Catlin BW. Auxotypes and antibacterial resistance of gonococci with differing susceptibilities to vancomycin. $\mathrm{Br} J$ Vener Dis 1982; 58: 166-175.

16. Knapp JS, Tam MR, Nowinski RC, Holmes KK, Sandström EG. Serological classification of Neisseria gonorrhoeae with use of monoclonal antibodies to gonococcal outer membrane protein I. J Infect Dis 1984; 150: 44-48.

17. Kohl PK, Knapp JS, Hofmann $\mathrm{H}$ et al. Epidemiological analysis of Neisseria gonorrhoeae in the Federal Republic of Germany by auxotyping and serological classification using monoclonal antibodies. Genitourin Med 1986; 62: 145-150.

18. Moyes A, Young $\mathrm{H}$. Typing of Neisseria gonorrhoeae by auxotype, serovar and lectin agglutination. $\mathrm{Br} J$ Biomed Sci 1993; 50: 295-300.

19. Faur YC, Weisburd MH, Wilson ME, May PS. A new medium for the isolation of pathogenic Neisseria (NYC medium). I. Formulation and comparisons with standard media. Hlth Lab Sci 1973; 10: 44-54.

20. Faur YC, Weisburd MH, Wilson ME. The selectivity of vancomycin and lincomycin in NYC medium for the recovery of $N$. gonorrhoeae from clinical specimens. Hlth $\mathrm{Lab} \mathrm{Sci}$ 1978; 15: 22-27.

21. Odegaard K, Solberg O, Lind J, Myhre G, Nyland B. Lincomycin in selective media for the isolation of Neisseria gonorrhoeae. Acta Pathol Microbiol Scand (B) 1975; 83: 
301-304.

22. Hookham AB. Thayer-Martin medium and modified New York City medium for the cultural diagnosis of gonorrhoea. $\mathrm{Br} J$ Vener Dis 1981; 57: 213.

23. Svarva PL, Maeland JL. Comparison of two selective media in the cultural diagnosis of gonorrhoea. Acta Pathol Microbiol Scand (B) 1979; 87: 391-392.

24. Granato PA, Schneible-Smith C, Weiner LB. Use of New York City medium for improved recovery of Neisseria gonorrhoeae from clinical specimens. J Clin Microbiol 1981; 13: 963-968.

25. Kohl PK, Pekar U, Hoffmann H, Petzoldt D. Characterization of Neisseria gonorrhoeae isolates from prostitutes with single and multiple infections. In: Poolman JT, Zanen HC, Meyer TF et al. (eds) Gonococci and meningococci. Dordrecht, Kluwer Academic Publishers. 1987: 143-146.

26. Faur YC, Weisburd MH, Wilson ME. A new medium for the isolation of pathogenic Neisseria (NYC medium) II. Effect of amphotericin B and trimethoprim lactate on selectivity. Hlth Lab Sci 1973; 10: 55-60.
27. Fallon RJ, Young H. Neisseria: Acinetobacter: Branhamella. In: Collee JG, Duguid JP, Fraser AG, Marmion BP (eds) Mackie and McCartney Practical medical microbiology. Edinburgh, Churchill Livingstone. 1989: 360-373.

28. Knapp JS, Totten PA, Mulks MH, Minshew BM. Characterization of Neisseria cinerea, a nonpathogenic species isolated on Martin-Lewis medium selective for pathogenic Neisseria spp. $J$ Clin Microbiol 1984; 19: 63-67.

29. Boyce JM, Mitchell EB. Difficulties in differentiating Neisseria cinerea from Neisseria gonorrhoeae in rapid systems used for identifying pathogenic Neisseria species. J Clin Microbiol 1985; 22: 731-734.

30. Boyce JM, Mitchell EB, Knapp JS, Buttke TM. Production of 14C-labeled gas in BACTEC Neisseria Differentiation kits by Neisseria cinerea. J Clin Microbiol 1985; 22: 416-418.

31. Lawton WD, Koch LW. Comparison of commercially available New York City and Martin-Lewis medium for recovery of Neisseria gonorrhoeae from clinical specimens. J Clin Microbiol 1982; 16: 754-755. 